\title{
Modeling domestic pancake cooking incorporating the rheological properties of the batter. Application to seven batter recipes
}

\author{
Silvia Lorente-Bailo ${ }^{\mathrm{a}}$, Iñigo Etayo ${ }^{\mathrm{b}}$, María L. Salvador ${ }^{\mathrm{a}}$, Ana Ferrer-Mairal ${ }^{\mathrm{a}}$, Miguel A. \\ Martínez $^{\mathrm{b}, \mathrm{c}}$, Begoña Calvo ${ }^{\mathrm{b}, \mathrm{c}}$, Jorge Grasa ${ }^{\mathrm{b}, \mathrm{c}, *}$ \\ ${ }^{a}$ Plant Foods Research Group, Instituto Agroalimentario de Aragon IA2, Universidad de Zaragoza-CITA, \\ Miguel Servet 177, 50013 Zaragoza, Spain \\ ${ }^{b}$ Aragón Institute of Engineering Research (i3A), Universidad de Zaragoza, Spain. \\ ${ }^{c}$ Centro de Investigación Biomédica en Red en Bioingeniería, Biomateriales y Nanomedicina (CIBER-BBN), \\ Spain.
}

\begin{abstract}
A 2D axisymmetric model for coupled transient heat and mass transfer was developed to simulate pancake cooking on a domestic induction hob. Unlike previous models, the current model considers a variable thermal contact conductance resulting from the crust formation at the bottom of the batter. It aims to take into account the heat transfer phenomena between the pan surface and the batter influenced by the physicochemical changes that the batter undergoes during the cooking process. To quantify the variation of the heat flow that this change in the structure of the batter involves, a normalized relationship between batter viscosity and the temperature was introduced in the model. The performance of seven cereal and legume flour-based batters was evaluated in an experimental setup. The proposed model is capable of adequately predicting the weight loss and the average surface temperature of the batter using parameters related with the rheological properties of the batter and its composition.

Keywords: Pan cooking, water vaporization, batter viscosity, flour properties, finite element method
\end{abstract}

\footnotetext{
${ }^{*}$ Corresponding author: Mechanical Engineering Department, C/ Maria de Luna s/n, 50018 Zaragoza, Spain. Tel.: 34 876555288. E-mail address jgrasa@unizar.es.
} 


\section{Introduction}

Pan cooking for domestic heat processing of flour cereal products has not been traditionally as widely studied as oven baking in terms of heat and mass transfer (Kokolj et al., 2017; Zhang et al., 2017; Iribe-Salazar et al., 2018). Current models are unable to adequately predict the influence of batter composition on transfer phenomena. In the case of pancake cooking models, the thermal conductivity and density of the pancake are normally expressed as a function of the batter constituents (Feyissa et al., 2011; Sanz-Serrano et al., 2017) but this dependence is not enough to explain the evaporation rates during the pan cooking of different batters.

One of the fundamental challenges that numerical modelling faces is adaptability to the following factors: cooking hardware, foods with different physico-chemical properties, different formulation of recipes, and the natural variability, as a biological material, of the food properties. The parameter uncertainty is a major problem in physical-based models (Datta, 2008). They are commonly obtained from previous models in the literature or calculated by means of optimization, i.e., minimizing the differences with experimental data (Feyissa et al., 2011; Mercier et al., 2014; Sanz-Serrano et al., 2017). However, it would be more desirable for the pancake cooking models to relate the parameters involved in the heat and mass transfer with what phenomenologically occurs and with the batter pasting properties.

Pancake cooking modelling is a complex task due to the difficulty of tracking the heat transfer phenomena between the pan surface and the batter, the noticeable physicochemical transformations of the batter during the process, and the consequent modification in the thermal contact resistance. The internal structure changes from a viscous dough to a heterogeneous structure (Cernela et al., 2015; Guibert-Martin et al., 2017). The water migrates through the outer surface in the form of liquid or vapor, so the functional properties of different flours clearly affect the moisture transport. The temperature in the contact heated surface reaches 
high values, so that the proteins thermoset but the starch granules do not gelatinize. In the core, pasted starch granules act like the reinforcement material in a composite where the denatured proteins are the "mortar" (Donovan, 1977).

These changes are linked to the rheological properties. The ability of batter to retain small bubbles has been related to its viscosity, which varies with the flour (Turabi et al., 2008). The structure depends on the pasting properties of the batter (Kaur and Singh, 2005; Kaushal et al., 2012) and the consistency of the gel on the batter viscoelastic properties (Hesso et al., 2015). In turn, these rheological properties depend on the batter composition, the presence or lack of gluten, and the quantity and type of starch and fiber, among other factors. However, the rheological properties of the batter are normally not considered in the cooking modeling. Two exceptions are the work of Decindio and Correra (1995) which used the linear viscoelasticity of the batter to quantify the gas bubble expansion phenomenon, and (Lostie et al., 2002), which related the batter bulk velocity resulting from the volume expansion due to the overpressure of the gas phase with the bulk viscosity of the batter.

The main objective of this work is to relate the heat transfer phenomena between the pan surface and the batter with the physicochemical changes that the batter undergoes during the cooking process. It also aims to introduce a novel approach to simulate the domestic cooking of pancakes, allowing the application of the model to different recipes. Unlike previous models developed for pancake contact baking, this approach considers the changes in heat transfer properties as a consequence of the crust formation. Besides, it takes into account that some of the key characteristics of the model, such as the contact heating interface and water evaporation rate, are influenced by the relationship between the temperature and the batter viscosity. To achieve this goal, the basic physicochemical and rheological properties of seven batters were experimentally determined and an experimental setup was developed to reproduce the cooking process of these batters. The experimental results were used to obtain 
50 batter-dependent parameters in the model that provided key information about the cooking 51 performance of different compositions.

\section{Material and methods}

\subsection{Preparation of the batters}

Seven different batters were made using flours of wheat, whole spelt, whole oats, whole rice, corn, chickpea and lentil, obtained from local market. The following methods (AACC, 2000) were used for the approximate composition analysis of the flours: moisture (oven drying at $103{ }^{\circ} \mathrm{C}$, method no. $44-15 \mathrm{~A}$ ), ash (calcination at $550{ }^{\circ} \mathrm{C}$, method no. 08-01), lipids (extracted by Soxhlet utilizing petroleum ether as solvent, method no. 30-25), protein (Kjeldahl method, Nx5.7, method no. 46-10), fiber (method no. 32-05). Carbohydrate content was determined by the difference. The results of the different analyses are shown in Table 1.

\begin{tabular}{|c|c|c|c|c|c|c|}
\hline Ingredients & Moisture & Ash & Fat & Protein & Fiber & Carbohydrate \\
\hline \hline wheat flour & $14.50 \pm 0.15$ & $0.55 \pm 0.01$ & $1.40 \pm 0.01$ & $11.00 \pm 0.10$ & $2.40 \pm 0.02$ & $70.15 \pm 0.77$ \\
whole spelt flour & $11.72 \pm 0.12$ & $1.83 \pm 0.05$ & $3.60 \pm 0.04$ & $13.02 \pm 0.15$ & $5.83 \pm 0.04$ & $64.00 \pm 0.71$ \\
whole rice flour & $12.61 \pm 0.09$ & $1.39 \pm 0.03$ & $0.52 \pm 0.01$ & $6.50 \pm 0.07$ & $2.63 \pm 0.03$ & $76.35 \pm 0.79$ \\
whole oats flour & $9.66 \pm 0.12$ & $3.98 \pm 0.04$ & $7.89 \pm 0.09$ & $12.70 \pm 0.11$ & $9.67 \pm 0.10$ & $56.10 \pm 0.59$ \\
lentil flour & $8.70 \pm 0.11$ & $2.32 \pm 0.03$ & $1.83 \pm 0.03$ & $24.87 \pm 0.21$ & $8.33 \pm 0.09$ & $53.95 \pm 0.54$ \\
corn flour & $11.11 \pm 0.13$ & $2.08 \pm 0.02$ & $2.80 \pm 0.05$ & $9.01 \pm 0.08$ & $6.63 \pm 0.04$ & $68.37 \pm 0.71$ \\
chickpea flour & $8.07 \pm 0.09$ & $2.75 \pm 0.03$ & $5.68 \pm 0.08$ & $20.02 \pm 0.25$ & $13.12 \pm 0.12$ & $50.36 \pm 0.55$ \\
Egg & 77.69 & 0.38 (salt) & 9.66 & 11.59 & 0.0 & 0.68 \\
Whole Milk & 88.82 & 0.12 (salt) & 3.66 & 3.49 & 0.0 & 4.66 \\
\hline \hline
\end{tabular}

Table 1: Percentage of moisture and macronutrients of the ingredients (mean \pm standard deviation). For the eggs and milk, the data were obtained from the supplier. 
A pancake batter formulation containing flour $(26.77 \% \mathrm{w} / \mathrm{w})$, whole milk $(51.63 \% \mathrm{w} / \mathrm{w})$, pasteurized hen egg $(21.03 \%$ w/w) (Calidad Pascual, Aranda de Duero, Spain), and salt (0.57 $\% \mathrm{w} / \mathrm{w}$ ) was used in the experiments. First, the dry ingredients (flour and salt) were mixed thoroughly. In a separate bowl, the milk and egg were mixed, and then added to dry ingredients and mixed by hand for 1 min.

\subsection{Rheological analysis of batters}

The rheological behavior of the batters was measured using a MCR 301 rheometer (Anton Paar Physica, Austria) equipped with serrated parallel plate geometry (50 mm diameter, $1 \mathrm{~mm}$ gap). The batter was left to rest for 10 min after preparation. Samples were loaded between the plates, and any excess batter outside the plate edge was removed.

For the flow measurement, shear stress values were recorded for shear rates over a range of $0.1-300 \mathrm{~s}^{-1}$ for $7.5 \mathrm{~min}$. The data were fitted to the Power law model:

$$
\tau=K(\dot{\gamma})^{n}
$$

where $\tau$ is the shear stress $(\mathrm{Pa}), \dot{\gamma}$ is the shear rate $\left(\mathrm{s}^{-1}\right), K$ is the consistency index (Pa $\mathrm{s}^{n}$ ) and $n$ is the flow index.

To study the effect of the temperature on the rheological properties, rotational tests at a heating rate of $5{ }^{\circ} \mathrm{C} \mathrm{min}-1$ from $25{ }^{\circ} \mathrm{C}$ to $100{ }^{\circ} \mathrm{C}$ were carried out at a shear rate of $200 \mathrm{~s}^{-1}$ (selected to guarantee the existence of a linear range according to shear rate sweeps carried out previously). Vaseline oil was applied to prevent sample drying during the test. The following indexes were determined using the software provided with the instrument: viscosity at $25{ }^{\circ} \mathrm{C}$, $\eta_{25^{\circ} \mathrm{C}}$; pasting temperature, $T_{P}$, (temperature at which an increase in viscosity occurs); viscosity at the pasting temperature, $\eta_{T_{P}}$; peak viscosity, $\eta_{\max }$; and, peak temperature, $T_{\eta_{\max }}$, (maximum viscosity and temperature at this point). 
Oscillatory shear tests at $25{ }^{\circ} \mathrm{C}$ were conducted to characterize the viscoelastic behavior of the batter. Strain sweep tests were carried out in the range of 0.01 - $100 \%$ at constant frequency (3 Hz). The storage modulus $G^{\prime}$, the loss modulus $G^{\prime \prime}$ and the loss factor $\tan \delta=G^{\prime \prime} / G^{\prime}$, were recorded during the test.

All the measurements were performed five times for the seven different flour and batter preparations.

\subsection{Cooking conditions}

Pancakes were cooked in a forged aluminium $180 \mathrm{~mm}$ diameter and $5 \mathrm{~mm}$ thickness pan with a thin bottom steel layer and a non-stick coating (Easy Induction, Kuhn Rikon, Zell, Switzerland). An induction hob (BOSCH Schott Ceran 9000440134 model, BSH, Munich, Germany) was used at power level 8.5 to supply $947 \pm 4 \mathrm{~W}$. The batter (110 g to obtain a pancake of $3 \mathrm{~mm}$ thick) was added to the pan when a uniform temperature of $230 \pm 2{ }^{\circ} \mathrm{C}$ was reached, measured with an infrared thermal imager (875-2 model, Testo, Lenzkirch, Germany). All the preparations were cooked for $240 \mathrm{~s}$ and five replicates were performed.

The pancake weight loss during the cooking process was monitored by placing the hob on a balance (DS30K0.1L, Kern \& Sohn, Balinger-Frommern, Germay) with a measurement range from 0 to $30 \mathrm{~kg}$ and a precision of $0.1 \mathrm{~g}$ that records data every $1 \mathrm{~s}$. During the cooking time, a thermographic image of the upper side of the pancake was taken at $30 \mathrm{~s}$ intervals, and the radial temperature profiles were determined using the software Testo IRsoft (Instrumentos Testo S.A., Barcelona, Spain). A schematic diagram of the pancake cooking process is shown in Fig. 1. 


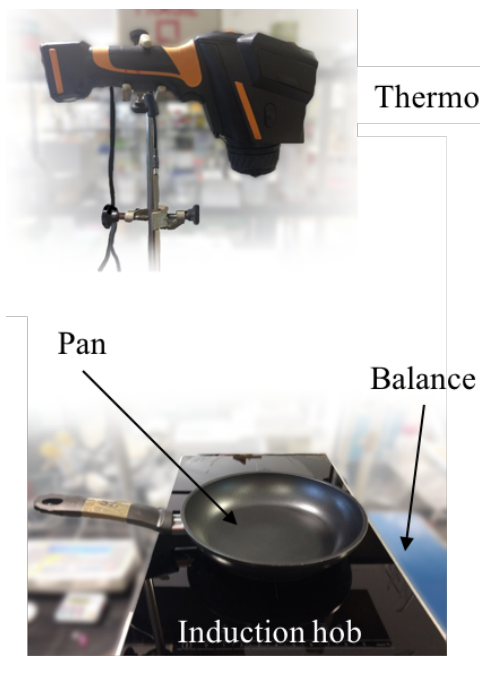

Heating up to $230^{\circ} \mathrm{C}$

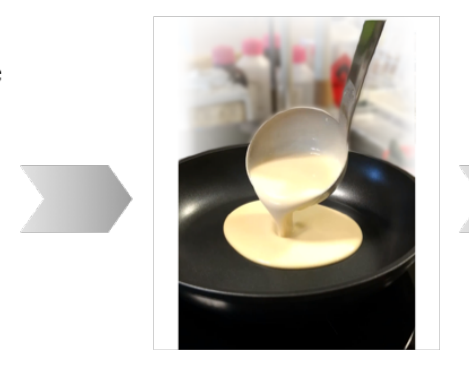

Addition of $100 \mathrm{~mL}$ of batter

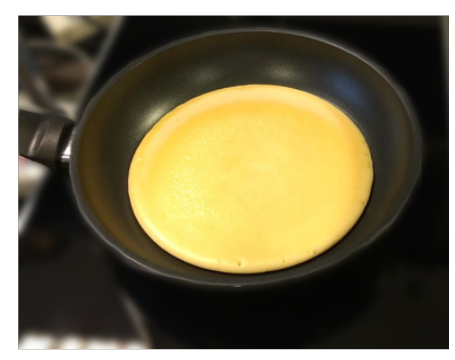

Cooking for $240 \mathrm{~s}$

Figure 1: Experimental pancake frying setup and cooking process.

\subsection{Statistical analysis}

Data are presented as the mean \pm standard deviation. The Statistical Package for Social Sciences (SPSS Inc, software version 22.0, Chicago, IL, USA) was used for the statistical analysis. Differences were considered significant at $P<0.05$. Analysis of variance was performed using one-way analysis of variance (ANOVA) followed by Duncan's post hoc test for comparison of means and least significant differences (LSD).

\subsection{Mathematical model}

\subsubsection{Hypothesis}

The cooking process of pancakes was modeled as a coupled transient heat and mass transfer problem where the product was heated by contact with the hot surface of the pan. The experimental setup was recreated using the same pan geometry and the power input distribution generated by the induction hob to heat the system. Nevertheless, our approach included 
several simplifying assumptions starting with an axysimmetric representation of the geometry and the heating flux power. Only energy and mass transport mechanisms were considered, assuming the pancake batter to be reasonably viscous. Moreover, the thickness was very low and no gas phase overpressure was assumed, which avoided having to account for any change of momentum of the batter bulk. The pan was heated by an inward heating flux, and heat was transferred to the batter with a very high thermal contact conductance. This drastically decreased when the viscosity increased as a crust was formed on the bottom of the batter in contact with the pan. The heat was transferred within the pancake batter by conduction, and convection to the air constituted the heat loss mechanism in the external surface. Liquid water diffused within the pancake batter, and local evaporation simultaneously occurred. Water and water vapor transport through the product were considered separately as multiphase transport species. Finally, water vapor generated in the pancake batter migrated to the top surface and subsequently diffused to the environment.

\subsubsection{Heat transfer}

The governing equation for the temperature evolution of the induction-heated pan was:

$$
P+\lambda_{A l} \nabla^{2} T=\rho_{A l} C_{A l} \frac{\partial T}{\partial t}
$$

where $P$ is the volumetric power density generated by the inductor at the bottom of the pan, $\lambda_{A l}$ is the thermal conductivity of the aluminium, $\rho_{A l}$ is the density and $C_{A l}$ was the specific heat of the pan material.

Inside the pancake, considering the water energy absorption during evaporation:

$$
\lambda_{p} \nabla^{2} T=\rho_{p} C_{p} \frac{\partial T}{\partial t}+Q_{e v p}
$$

34 where $Q_{\text {evp }}\left(\mathrm{W} / \mathrm{m}^{3}\right)$ is the heat dissipated by water evaporation, $\lambda_{p}$ is the thermal conductivity, 
expression was proposed:

$$
Q_{e v p}=\rho_{p} \sigma_{e v p} f_{v} L_{e v p}
$$

146 where $\sigma_{e v p}$ was an evaporation rate constant, $L_{e v p}$ water latent heat of vaporization obtained 147

$$
L_{\text {evp }}=2059.1 \cdot T^{\beta}+6604.5 \cdot T^{\beta+\Delta}+7694.3 \cdot T^{1-\alpha+\beta}-11318 \cdot T-4284.4 \cdot T^{2}+2598.6 \cdot T^{3}
$$


${ }_{148} \quad$ in $\mathrm{kJ} / \mathrm{kg}$, with $\alpha=\frac{1}{8}, \beta=\frac{1}{3}$ and $\Delta=0.5$.

${ }_{149} \quad f_{v}$ was an empirical normalized function:

$$
f_{v}= \begin{cases}\exp \left(-\left(\frac{T-T_{\eta_{\max }}}{\xi}\right)^{2}\right), & T \leq T_{\eta_{\max }} \\ 1, & T>T_{\eta_{\max }}\end{cases}
$$

150

151 152

Parameters $T_{\eta_{\max }}$ and $\xi$ were obtained from fitting the normalized relationship between the normalized batter viscosity and the temperature (Fig. 2). The values of these parameters for the seven batters are shown in Table 2.

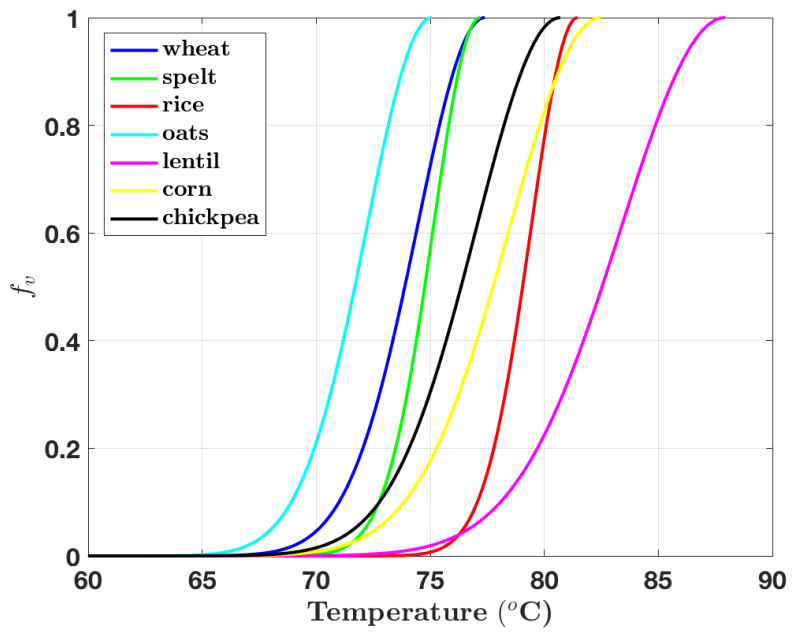

Figure 2: $f_{v}$ in Eq. (9) for the batters elaborated with the different flours.

\section{2.5.3. Mass transfer}

${ }_{154}$ Inside the pancake domain, the equations that govern the multiphase diffusion and water 155 evaporation were expressed as:

$$
\frac{\partial x_{l}}{\partial t}=\nabla\left(D_{l} \nabla x_{l}\right)-\sigma_{e v p} f_{v}, \quad \frac{\partial x_{v}}{\partial t}=\nabla\left(D_{v} \nabla x_{v}\right)+\sigma_{e v p} f_{v}
$$




\begin{tabular}{|c|c|c|c|}
\hline Flours & $T_{\eta_{\max }}\left({ }^{\circ} \mathrm{C}\right)$ fitted & $\xi\left({ }^{\circ} \mathrm{C}\right)$ & $R^{2}$ \\
\hline \hline Wheat & 74.7 & 3.33 & 0.9941 \\
Whole spelt & 75.4 & 2.09 & 0.9951 \\
Whole rice & 79.7 & 1.97 & 0.9947 \\
Whole oats & 72.4 & 2.78 & 0.9938 \\
Lentil & 80.5 & 2.99 & 0.9922 \\
Corn & 78.5 & 4.13 & 0.9859 \\
Chickpea & 76.9 & 2.86 & 0.9644 \\
\hline
\end{tabular}

Table 2: Parameters of different batters in Eq. 9.

The constraint is $x_{s}+x_{l}+x_{v}=1$. $D_{l}$ and $D_{v}$ are the water and vapor diffusion coefficients and $\sigma_{\text {evp }} f_{v}$ is the rate of water evaporation.

\subsubsection{Initial and Boundary Conditions}

An initial uniform temperature of $230{ }^{\circ} \mathrm{C}$ was considered for the pan; for the batter, the uniform room temperature was applied $\left(T_{0}=20{ }^{\circ} \mathrm{C}\right)$. An input heat source was applied to the bottom region of the pan to simulate the inductive power. No vapor content was considered in this initial state.

Regarding heat transfer, the conduction mechanism was considered between the contacting surfaces of the glass and the pan through a contact conductance:

$$
-\lambda_{A l} \nabla T=-\lambda_{g} \nabla T=h_{c}\left(T_{g}-T_{A l}\right)
$$

where $h_{c}=50\left(\mathrm{~W} /\left(\mathrm{K} \mathrm{m}^{2}\right)\right)$ is the contact conductance (Sanz-Serrano et al., 2017) and $T_{g}$ and $T_{A l}$ are the temperatures at the glass and the aluminium pan, respectively.

During cooking, the cereal or legume batter transforms from a viscous dough to a hetero- 
geneous structure, which drastically modifies the thermal contact behavior with the pan. In this work, a time dependent contact conductance was introduced considering the normalized relationship between the batter viscosity and the temperature:

$$
-\lambda_{A l} \nabla T=-\lambda_{p} \nabla T=h_{c p}\left(1-f_{v}\right)\left(T-T_{A l}\right)
$$

The bottom surface of the glass of the induction system was considered adiabatic, since the temperature of the coil and air in the real system was close to the glass temperature therefore, heat fluxes were negligible.

The natural heat convection mechanism was considered in the external wall of the pan, whereas the heat flux between the batter and the air was considered using a coefficient $h_{p}$ :

$$
-\lambda_{p} \nabla T=h_{p}\left(T-T_{\text {air }}\right)
$$

Only mass flow of vapor was allowed through the top surface of the pancake:

$$
-D_{v} \nabla x_{v}=k_{v} \rho_{p}\left(x_{v}-x_{v_{a}}\right)
$$

where $k_{v}$ is the vapor mass transfer coefficient; $x_{v_{a}}=x_{v_{a}}^{\prime} \frac{\rho_{a}}{\rho_{p}}$ is the humidity of the surrounding air, which is expressed in terms of product mass; $x_{v_{a}}^{\prime}$ is the vapor fraction and $\rho_{a}$ is the air density at ambient temperature (Sanz-Serrano et al., 2017).

\subsection{Finite element model}

An axisymmetric computational model was developed in COMSOL Multi-physics ${ }^{\circledR}$ v.5.2a to reproduce the contact baking process considering three different parts. As shown in Fig. 3 , the vitroceramic glass had a thickness of $4 \mathrm{~mm}$; and the aluminium pan had an internal diameter of $180 \mathrm{~mm}, 5 \mathrm{~mm}$ thickness and the lateral wall was $50 \mathrm{~mm}$ height. Finally, the pancake diameter was identical to the interior diameter of the pan and the pancake was $3 \mathrm{~mm}$ 
thick. A mesh sensitivity analysis was conducted to find a suitable mesh size with the optimum computational efficiency for the optimization process. The selected discretization consisted of 1788 quadrilateral elements using quadratic approximation for both the mass and heat transfer (Fig. 3.a). Automatic time increments were taken by the implicit backward differentiation method and solution outcomes were saved every $1 \mathrm{~s}$.

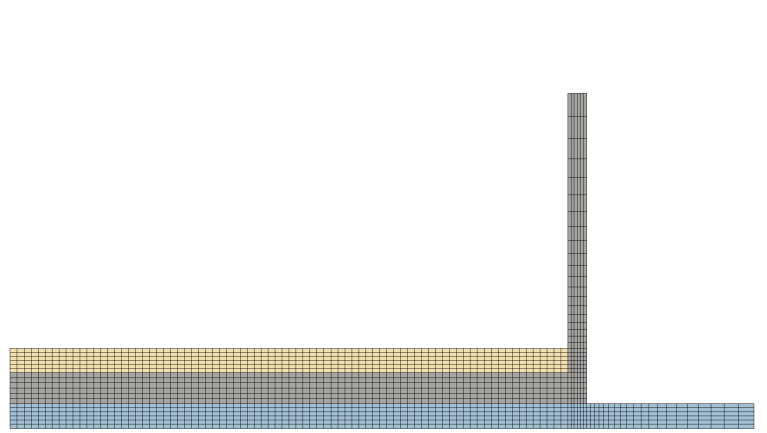

(a)

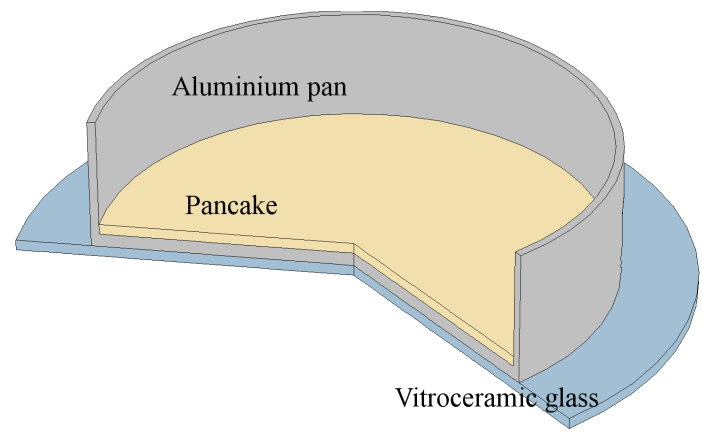

(b)

Figure 3: a) Two-dimensional axisymmetric finite element mesh. b) Three-dimensional representation of the different parts of the computational model.

The power-density field acting in the pan via the induction hob was obtained from the literature (Sanz-Serrano et al., 2017) with a certain degree of modification to apply the experimental power level. The simulation time was fixed at $240 \mathrm{~s}$ as the experimental cooking time.

\section{Results and Discussion}

\subsection{Experimental results}

To determine the role of the composition (Table 1) in the rheological properties and the cooking behavior of the batter, several flours from different sources were selected. The flow curves, which show the variation of the shear stress with the shear rate, are shown in Fig. 4.a. 
The experimental data were fitted to the power law Eq. (1), with coefficients of determination $\left(R^{2}\right)$ higher than 0.997 , except for the batter made with oats flour $\left(R^{2}=0.975\right)$. The power law model parameters are showed in Table 3. The flow index $n$ was $0.325-0.764$ which denotes the deviation from being Newtonian fluids. The batters showed a typical shear-thinning (pseudoplastic) behavior, where the apparent viscosity decreased with the increase in the shear rate due to the alignment of the microstructure with the flow direction. All the samples showed low consistency $K$ than those reported for sponge cakes (Huang and Yang, 2019). Batter consistency is related to the air incorporation and retention during baking (Turabi et al., 2008). The flow index $n$ was significantly lower and $K$ much higher $(P<0.05)$ in the whole spelt and chickpea batters than in the others, indicating greater pseudoplasticity and consistency in those batters under large deformations. The high amounts of protein and fiber in these flours (Table 1) reduced the amount of free water available, limiting the movement of particles in the batter, and thus giving a high consistency index. The rice batter showed the lowest consistency, which demonstrated a limited bubble holding capacity, due to the low protein content and the low solubility and functionality of these rice proteins. 


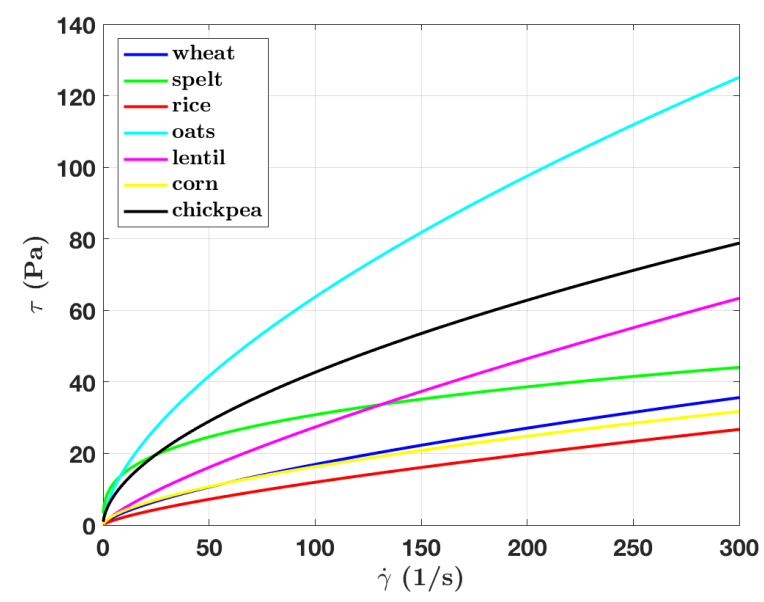

(a)

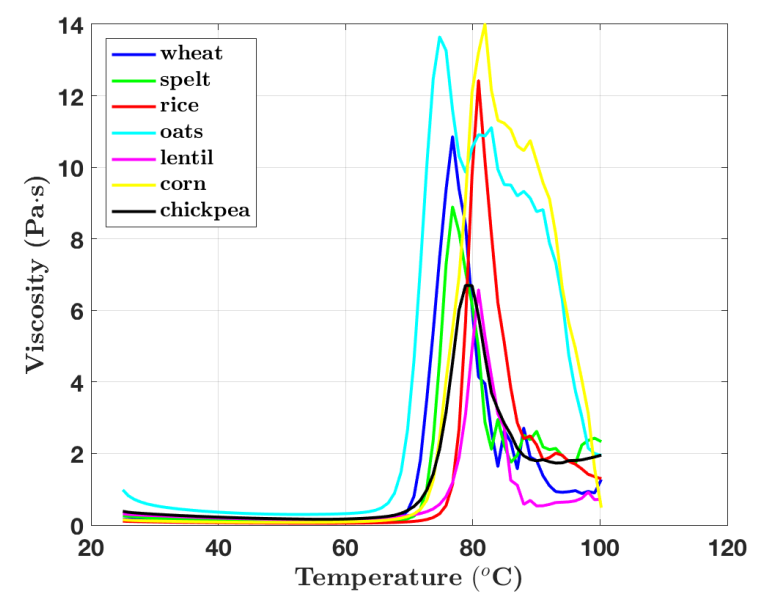

(b)

Figure 4: a) Experimental results of the shear stress curves of the seven batters. b) Temperature dependence of the viscosity experimentally obtained for the seven batters.

\begin{tabular}{|c|c|c|c|}
\hline Batter & $K\left(\mathrm{~Pa} \cdot \mathrm{s}^{n}\right)$ & $n$ & $R^{2}$ \\
\hline \hline wheat & $0.754 \pm 0.014^{a}$ & $0.676 \pm 0.003^{d}$ & 0.999 \\
whole spelt & $6.905 \pm 0.089^{c}$ & $0.325 \pm 0.002^{a}$ & 0.997 \\
whole rice & $0.411 \pm 0.003^{a}$ & $0.732 \pm 0.002^{e}$ & 1.000 \\
whole oats & $3.771 \pm 0.304^{b}$ & $0.614 \pm 0.015^{c}$ & 0.975 \\
lentil & $0.812 \pm 0.010^{a}$ & $0.764 \pm 0.002^{e}$ & 0.999 \\
corn & $1.002 \pm 0.015^{a}$ & $0.606 \pm 0.003^{c}$ & 0.999 \\
chickpea & $3.268 \pm 0.040^{b}$ & $0.558 \pm 0.002^{b}$ & 0.999 \\
\hline \hline
\end{tabular}

Table 3: Power law model constants for different batters: consistency index $(K)$, flow index $(n)$ and coefficient of determination $\left(R^{2}\right)$. The values are means \pm standard deviation of the replicates. The values followed by different letters in the same column are significantly different according to the Duncan's test $(P<0.05)$. 
Table 4 shows the initial viscosity $\eta_{25^{\circ} \mathrm{C}}$ and the pasting properties of the different batters obtained from the temperature sweep test. The batters had a low initial viscosity, $\eta_{25^{\circ} \mathrm{C}}<1$ Pa.s, which was even lower than those reported for crêpes (Guibert-Martin et al., 2017). Batter viscosity should be enough to retain bubbles and prevent settling but not so high as to allow the production of pancakes as sticky textured products. Besides, the generation of convection currents in the batter during baking is dependent on the initial batter viscosity and on the evolution of bulk viscosity during heating (Martinez-Cervera et al., 2012). Rice and corn flour had the lowest viscosity values, linked to their low protein content. These results are consistent with those reported in the bibliography (Turabi et al., 2008; Guadarrama-Lezama et al., 2016; Sahagún et al., 2018). This characteristic has been correlated with a denser structure of the baked products (Baixauli et al., 2008). The legume batters showed higher viscosities than the wheat batters, as other authors have also observed (Alvarez et al., 2017), due to their richness in fiber, which are 3.5 and 5.5 times greater, respectively, for lentil and chickpea than for wheat flour (Table 1). The legume flours also have the highest protein contents, indicating a marked potential to absorb moisture and a remarkable emulsifying capacity. The oats batter showed the highest values, due to their high content of $\beta$-glucans. A high positive correlation was found between viscosity and soluble $\beta$-glucan contents (Ahmad et al., 2009; Gularte et al., 2012; de La Hera et al., 2013).

During baking at temperatures below $60^{\circ} \mathrm{C}$, the viscosity slightly decreased to a minimum value (Fig. 4.b) allowing the air bubbles to move and increase their size. When the temperature reached $60{ }^{\circ} \mathrm{C}$, a rapid increase in viscosity was observed as previously described (GuibertMartin et al., 2017). This increase was linked to starch gelatinization, egg protein denaturation and coagulation, and water evaporation.

The pasting temperatures ranged between $59.9{ }^{\circ} \mathrm{C}$ (wheat) and $69.2{ }^{\circ} \mathrm{C}$ (corn), and the maximum viscosity values were obtained at temperatures between $75.3^{\circ} \mathrm{C}$ (oats) and $81.9{ }^{\circ} \mathrm{C}$ 


\begin{tabular}{|c|c|c|c|c|c|}
\hline Batter & $\eta_{25^{\circ} C}(\mathrm{~Pa} \cdot \mathrm{s})$ & $\eta_{T_{P}}(\mathrm{~Pa} \cdot \mathrm{s})$ & $T_{P}\left({ }^{o} \mathrm{C}\right)$ & $\eta_{\max }(\mathrm{Pa} \cdot \mathrm{s})$ & $T_{\eta_{\max }}\left({ }^{o} \mathrm{C}\right)$ \\
\hline \hline wheat & $0.162 \pm 0.021^{a}$ & $0.074 \pm 0.006^{a}$ & $59.9 \pm 0.1^{a}$ & $10.857 \pm 0.915^{c}$ & $77.0 \pm 0.0^{b}$ \\
whole spelt & $0.259 \pm 0.017^{b}$ & $0.105 \pm 0.004^{b}$ & $62.6 \pm 0.8^{b}$ & $8.896 \pm 0.644^{b}$ & $77.3 \pm 0.6^{b}$ \\
whole rice & $0.108 \pm 0.003^{a}$ & $0.072 \pm 0.014^{a}$ & $67.1 \pm 1.9^{d}$ & $12.423 \pm 0.415^{d}$ & $81.0 \pm 0.0^{d}$ \\
whole oats & $0.984 \pm 0.122^{d}$ & $0.365 \pm 0.011^{e}$ & $63.3 \pm 0.6^{b c}$ & $13.645 \pm 1.202^{e}$ & $75.3 \pm 0.5^{a}$ \\
lentil & $0.315 \pm 0.027^{b c}$ & $0.192 \pm 0.008^{c}$ & $64.5 \pm 1.0^{c}$ & $6.577 \pm 1.076^{a}$ & $81.3 \pm 0.5^{d}$ \\
corn & $0.153 \pm 0.003^{a}$ & $0.213 \pm 0.002^{d}$ & $69.2 \pm 0.5^{e}$ & $14.000 \pm 0.071^{e}$ & $81.9 \pm 0.0^{e}$ \\
chickpea & $0.385 \pm 0.020^{c}$ & $0.196 \pm 0.013^{c}$ & $63.4 \pm 0.4^{b c}$ & $6.698 \pm 0.322^{a}$ & $79.5 \pm 0.5^{c}$ \\
\hline \hline
\end{tabular}

Table 4: Pasting properties for different batters. The values are means \pm standard deviation of the replicates. The values followed by different letters in the same column are significantly different according to the Duncan's test $(P<0.05)$.

(corn). The gluten free cereal flours, corn and rice, showed the highest pasting temperatures. Pasting properties are mainly affected by starch type and quantity, and the results indicate that starch-protein interactions decreased the $T_{p}$ and $\eta_{\max }$ values.

The mechanical spectra for all the batters showed values of the storage modulus $\left(G^{\prime}\right)$ higher than those of loss modulus $\left(G^{\prime \prime}\right)$, typical behavior of soft gels and a weak structural network (Table 5). For wheat samples, $\tan \delta$ was 0.98 , with similar moduli $G^{\prime}$ and $G^{\prime \prime}$, indicating more viscous and less elastic behavior. However, the value of $\tan \delta$ for the batter formulated with spelt flour was 0.27 , reflecting a more structured and solid like behavior. Spelt has recently been described as having higher protein and gluten content than common wheat (Geisslitz et al., 2019). The use of legume flours (chickpea and lentil) induced a hardening effect on the batter structure (increase in $G^{\prime}$ and $G^{\prime \prime}$ ) compared to wheat batter, due to their higher content in proteins and fiber, showing a similar effect to that reported by Matos et al. (2014) for other legumes. The $G^{\prime}$ strongly depended on the strain; consequently, the loss angle increased with 

(Guadarrama-Lezama et al., 2016).

\begin{tabular}{|c|ccc|c|}
\hline \multirow{2}{*}{ Batter } & $G^{\prime}(\mathrm{Pa})$ & $G^{\prime \prime}(\mathrm{Pa})$ & $\tan \delta$ & $\begin{array}{c}\text { Strain }(\%) \\
\text { at } \tan \delta=1\end{array}$ \\
& in the linear range $(0.1 \%$ of strain $)$ & \\
\hline \hline wheat & $8.86 \pm 0.80^{a}$ & $8.66 \pm 0.06^{a b}$ & $0.98 \pm 0.09^{e}$ & $0.27 \pm 0.02^{a}$ \\
whole spelt & $279.13 \pm 35.47^{c}$ & $75.75 \pm 8.25^{e}$ & $0.27 \pm 0.01^{a}$ & $12.95 \pm 0.43^{e}$ \\
whole rice & $5.50 \pm 0.20^{a}$ & $4.73 \pm 0.02^{a}$ & $0.86 \pm 0.03^{d}$ & $0.89 \pm 0.07^{b}$ \\
whole oats & $53.44 \pm 6.34^{b}$ & $25.38 \pm 1.18^{d}$ & $0.48 \pm 0.03^{b}$ & $3.29 \pm 0.25^{d}$ \\
lentil & $21.56 \pm 4.21^{a}$ & $12.99 \pm 2.40^{b c}$ & $0.60 \pm 0.01^{b}$ & $1.75 \pm 0.11^{c}$ \\
corn & $5.62 \pm 1.92^{a}$ & $3.51 \pm 0.53^{a}$ & $0.66 \pm 0.10^{b}$ & $0.89 \pm 0.07^{b}$ \\
chickpea & $29.23 \pm 4.38^{a b}$ & $17.89 \pm 4.02^{c}$ & $0.61 \pm 0.04^{b}$ & $1.91 \pm 0.14^{c}$ \\
\hline \hline
\end{tabular}

Table 5: Viscoelastic measurements for different batters. The values are means \pm standard deviation of the replicates. The values followed by different letters in the same column are significantly different according to the Duncan's test $(P<0.05)$.

the strain. The strain at which the change from solid-like $(\tan \delta<1)$ to liquid-like behavior $(\tan \delta>1)$ occurred is shown in Table 5. The strain values at $\tan \delta=1$ was extremely high for whole spelt (12.95) and low for wheat (0.27), rice and corn (0.89). Low values have been related with an increased tendency to flow and thus with fragile batter microstructures$$
\text { the }
$$

$$
\text { pre }
$$

21

throughout the cooking process. 


\begin{tabular}{|c|c|c|c|l|}
\hline Flours & $\begin{array}{l}\rho_{p_{0}} \\
\text { Density }\left(\mathrm{kg} / \mathrm{m}^{3}\right)\end{array}$ & $x_{l_{0}}$ & $x_{s_{0}}$ & $\begin{array}{l}C_{P_{p_{0}}} \\
\text { Specific heat } \\
(\mathrm{J} / \mathrm{kg} \mathrm{K})\end{array}$ \\
\hline \hline Wheat & 1135.11 & 0.6812 & 0.3188 & 3357.82 \\
Whole spelt & 1141.09 & 0.6738 & 0.3262 & 3344.96 \\
Whole rice & 1138.53 & 0.6762 & 0.3238 & 3337.73 \\
Whole oats & 1151.55 & 0.6683 & 0.3317 & 3335.85 \\
Lentil & 1135.66 & 0.6657 & 0.3343 & 3337.90 \\
Corn & 1142.06 & 0.6722 & 0.3278 & 3335.43 \\
Chickpea & 1143.64 & 0.6640 & 0.3360 & 3335.47 \\
\hline
\end{tabular}

Table 6: Initial density, mass fractions and specific heat at ambient temperature for different batters made with the seven flour types.

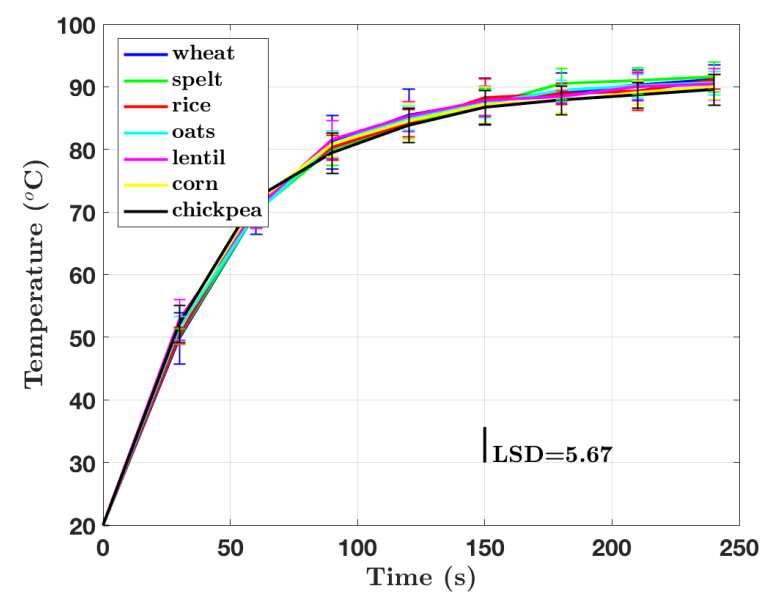

(a)

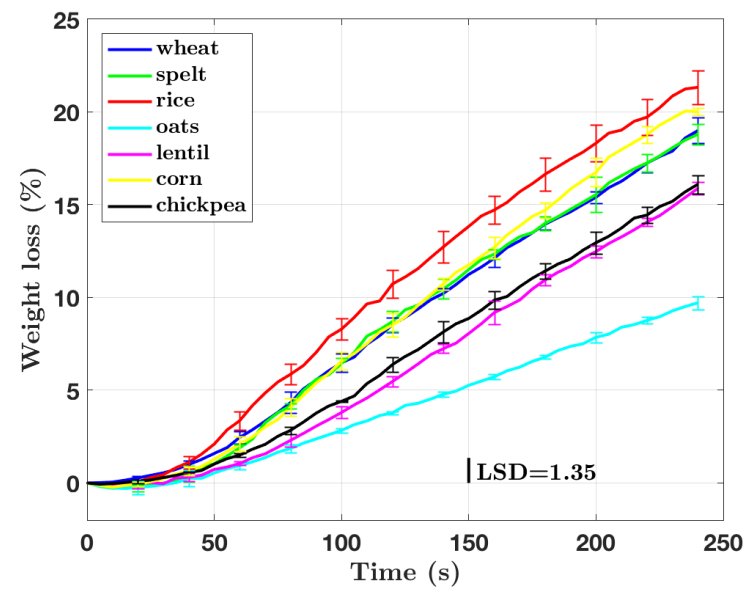

(b)

Figure 5: Experimental results of the average surface temperature and weight loss. The data shown are the means $( \pm)$ standard deviation of five replicates. Vertical bar $=$ pooled least significant differences (LSD) at the $5 \%$ level. 


\subsection{Numerical results}

Seven different models were developed using the initial batter compositions and properties as shown in Table 6. Using a gradient-based optimization algorithm implemented in the Comsol software (SNOPT), two objective functions were established based on the experimental temperature and weight loss observations. The algorithm considered eight control variables: the evaporation rate $\left(\sigma_{e v p}\right)$, water and vapor diffusion coefficients $\left(D_{v}\right.$ and $\left.D_{l}\right)$, the vapor mass transfer coefficient $\left(k_{v}\right)$, the thermal conductivity of the pancake related parameters $(a$ and $b$ ), the convective heat transfer coefficient between the pancake and the air $\left(h_{p}\right)$ and the initial heat contact conductance $\left(h_{c p}\right)$. These variables were selected due to their variability according to the data available in the literature.

As observed in Table 7, the highest values of $\sigma_{e v p}, D_{v}$ and $D_{l}$ were obtained for the rice flour batter. These parameters governed the rate of water evaporation in Eq. (7) and the diffusion of water in the form of vapor an liquid (see Eq. (10)). As mentioned, the rice batter, due to its low protein and fiber content, showed the lowest consistency $K$ which represented the lowest bubble holding capacity that enabled the rapid evaporation and vapor loss through the batter surface. The opposite effect was observed in the batter whole oats, rich in $\beta$-glucans. Higher consistency values were associated with the lower values of $\sigma_{e v p}$ and the vapor diffusivity $D_{v}$ predicted by the model. Moreover, the vapor mass transfer coefficient $k_{v}$ in Eq. (14) for the whole oat batter is the lowest to fit the objective of weight loss in Fig. 5.b. Due to the novelty of this study regarding the non wheat-batter flours, no previous results were found in the literature to contrast the value of these parameters. However, some previous studies proposed equivalent developments for contact baking of pancakes with wheat flour. In the work of SanzSerrano et al. (2017), the rate $\sigma_{e v p}=5.44 \cdot 10^{-4} \mathrm{~s}^{-1}$ was determined after an optimization process and Feyissa et al. (2011) fitted the same rate to experimental results with a mean value of $\sigma_{e v p}=11.4 \cdot 10^{-5} \mathrm{~s}^{-1}$. The diffusivity parameters and the mass transfer coefficient 

reproduce the behavior of other batter compositions.

\begin{tabular}{|c|c|c|c|c|c|c|c|}
\hline Flours & $\begin{array}{l}\sigma_{e v p} \\
\left(\mathrm{~s}^{-1}\right)\end{array}$ & $\begin{array}{c}D_{v} \\
\left(\mathrm{~m}^{2} \mathrm{~s}^{-1}\right)\end{array}$ & $\begin{array}{c}D_{l} \\
\left(\mathrm{~m}^{2} \mathrm{~s}^{-1}\right)\end{array}$ & $\begin{array}{c}k_{v} \\
(\mathrm{~m} / \mathrm{s})\end{array}$ & $\begin{array}{c}a \\
(\mathrm{~W} /(\mathrm{m} \mathrm{K}))\end{array}$ & $\begin{array}{c}b \\
(\mathrm{~W} /(\mathrm{m} \mathrm{K}))\end{array}$ & $\begin{array}{c}h_{p} \\
\left(\mathrm{~W} /\left(\mathrm{m}^{2} \mathrm{~K}\right)\right)\end{array}$ \\
\hline Wheat & $5.1623 \cdot 10^{-4}$ & $9.6599 \cdot 10^{-8}$ & $4.3337 \cdot 10^{-10}$ & 0.0421 & 0.8026 & 0.8374 & 14.4698 \\
\hline Whole spelt & $5.2813 \cdot 10^{-4}$ & $1.6153 \cdot 10^{-7}$ & $1.8579 \cdot 10^{-9}$ & 0.0555 & 0.8218 & 0.6395 & 14.8464 \\
\hline Whole rice & $6.5610 \cdot 10^{-4}$ & $4.1314 \cdot 10^{-7}$ & $4.4596 \cdot 10^{-9}$ & 0.0639 & 0.7776 & 0.5290 & 14.9739 \\
\hline Whole oats & $3.0727 \cdot 10^{-4}$ & $4.2502 \cdot 10^{-8}$ & $1.5381 \cdot 10^{-9}$ & 0.0023 & 0.9280 & 0.6370 & 15.2623 \\
\hline Lentil & $4.4458 \cdot 10^{-4}$ & $9.8016 \cdot 10^{-8}$ & $6.9666 \cdot 10^{-10}$ & 0.0459 & 0.8873 & 0.5821 & 14.9858 \\
\hline Corn & $5.7626 \cdot 10^{-4}$ & $1.2582 \cdot 10^{-8}$ & $1.6668 \cdot 10^{-9}$ & 0.0493 & 0.9291 & 0.7475 & 14.9846 \\
\hline Chickpea & $4.6349 \cdot 10^{-4}$ & $8.0770 \cdot 10^{-7}$ & $7.9541 \cdot 10^{-10}$ & 0.0474 & 0.8989 & 0.6864 & 14.9901 \\
\hline
\end{tabular}

Table 7: Optimization results of the parameters in the model for the batters made with different flours.

showed slight differences with those used by the above-mentioned authors. Different model assumptions, including product thicknesses and the the method to obtain other parameters, may be the cause of this discrepancy. In addition, it should be noted that the parameters provided by those previous works (Feyissa et al., 2011; Sanz-Serrano et al., 2017) are unable to 
conductance and the evolution of the heat transfer properties of the product, and consequently the rate of vapor generation in the bottom of the pancake decreases. The temperature at which these changes occur and their intensity depends on the batter characteristics, and specifically, as has been postulated in this work, on the rheological properties of the batter. On the other hand, the factors that most influence the rheological properties of the batters are the content and type of proteins and fiber. Therefore, it seems that these compositional aspects of the mass are what regulate the changes in the transport phenomena resulting from the crust formation. Although it has been experimentally described (Cernela et al., 2015; Guibert-Martin et al., 2017), to the best of our knowledge the crust formation and its consequence for the transport phenomena has not been modeled in the contact baking of flour products.

The parameters that controlled the heat conductivity of the batter in (Eq. 4), $a$ and $b$ did not greatly vary among the different batters. Basically, the expression that provides the equivalent thermal conductivity $\lambda_{p}$ of the material considered the conductivity of the water together with dispersed phases (Rao et al., 2005). When the porosity of the batter increased, this conductivity decreased taking as a limit the conductivity of the air. Lostie et al. (2002) used the same expression for the thermal conductivity in the oven baking of cakes and obtained similar parameter values.

According to the values of the convection coefficient $h_{p}$, which regulated the heat exchange with the air at the upper surface of the pancake in Eq. (13), this mechanism was identical in all the models. The values predicted were in the same magnitud order as those in previous models for contact baking simulation (Feyissa et al., 2011; Sanz-Serrano et al., 2017).

The temperature evolution in the models was always whithin the standard deviation region of the experiments, which is represented by the gray area in Fig. 6 except for the initial $30 \mathrm{~s}$. At the beginning of the heating process, the model stablished a non linear behavior in good agreement with that observed in previous studies (Feyissa et al., 2011; Cernela et al., 2015; 
Sanz-Serrano et al., 2017). The manual operation of the infrared camera precluded sampling at high frequencies to capture the initial heating evolution. The model predicted nearly the same high temperature levels at the end of the cooking process: the chickpea flour batter had the lowest value $\left(92{ }^{\circ} \mathrm{C}\right)$ and the the spelt flour batter the highest $\left(94.8^{\circ} \mathrm{C}\right)$. The experimental results show that the lowest value at $240 \mathrm{~s}$ corresponded to the chickpea flour batter with $89.6 \pm 2.5{ }^{\circ} \mathrm{C}$ and the highest to the spelt flour batter with $91.6 \pm 2.4{ }^{\circ} \mathrm{C}$. In Fig. 6 the root mean square error (RMSE) between the mean of the experimental temperature evolution and the model prediction is presented for each batter. This parameter represents a measure of how close are the simulated and the experimental temperatures. For all the batters this error is equal or less than $2.7^{\circ} \mathrm{C}$.

The simulation results for the batter weight loss and the experimental replications are presented in Fig. 7. The highest amount of weight loss in the experimental results corresponded to the rice flour batter $(21.3 \pm 1.0 \%)$, for which the model predicted a decrease of $23.6 \%$. The oat flour batter had the smallest weight loss (only $9.7 \pm 0.4 \%$ ), whereas the model provided 10.8 $\%$ at the end of cooking time. All the model outcomes showed the same tendency in the weight loss evolution during the heating process, which were close to the experimental observations. As qualitatively observed, some models (i.e., lentil flour batter) perform better than others regarding the proximity of the simulated curve to the experimental one. Quantitatively, the RMSE between the mean of the experimental results and the model predictions shows the lowest value for the lentil flour batter (0.35\%). A comparison with the available data in the literature shows that similar results were obtained in Sanz-Serrano et al. (2017) for the wheat flour batters but, when the thickness of the pancake increase the weight loss decreased (Feyissa et al., 2011; Cernela et al., 2015) 


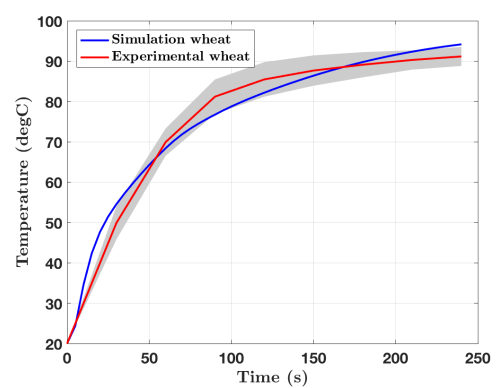

(a) $\mathrm{RMSE}=2.7^{\circ} \mathrm{C}$

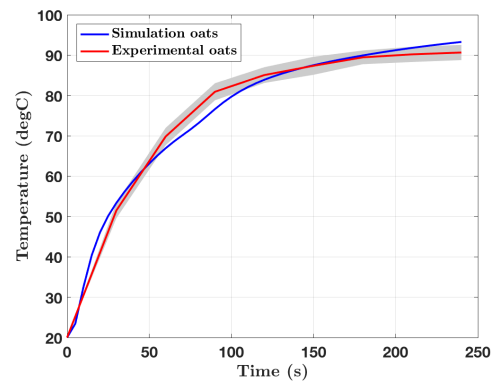

(d) $\mathrm{RMSE}=2.1^{\circ} \mathrm{C}$

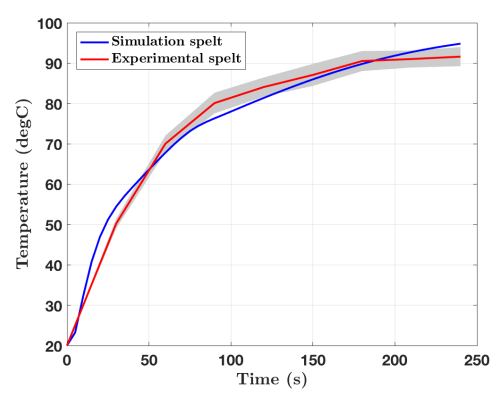

(b) $\mathrm{RMSE}=2.5^{\circ} \mathrm{C}$

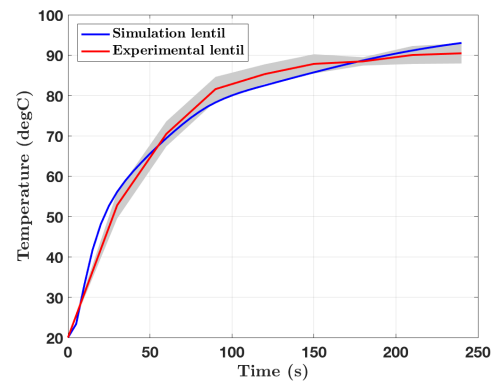

(e) $\operatorname{RMSE}=2.1^{\circ} \mathrm{C}$

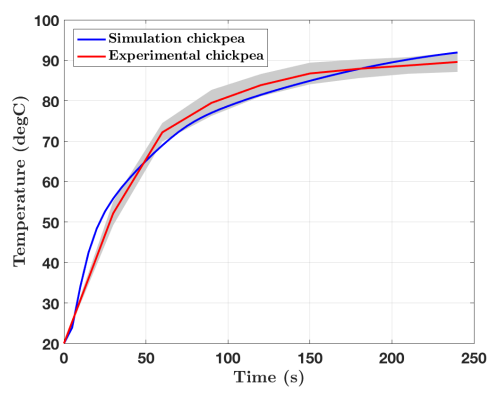

(g) $\mathrm{RMSE}=2.2^{\circ} \mathrm{C}$

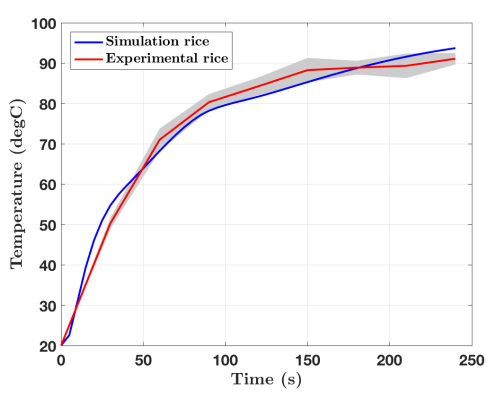

(c) $\operatorname{RMSE}=2.5^{\circ} \mathrm{C}$

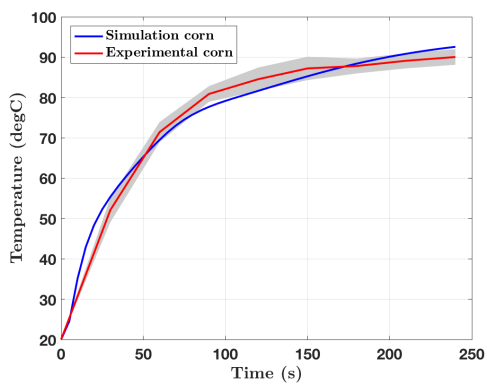

(f) $\operatorname{RMSE}=2.3^{\circ} \mathrm{C}$

Figure 6: Comparison of the simulated and measured average temperature evolutions for different batter compositions. The gray area in the figures represents the experimental standard deviation. The root mean square errors (RMSE) between the mean of the experimental results and the model prediction are presented under the figures. 


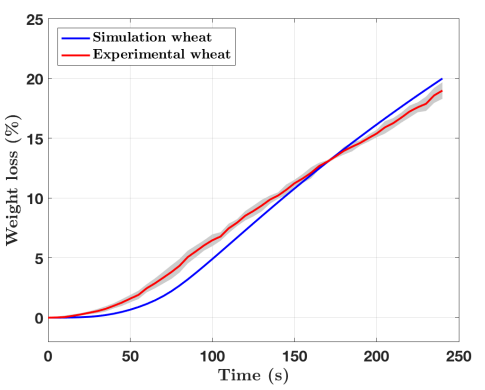

(a) $\mathrm{RMSE}=0.97 \%$

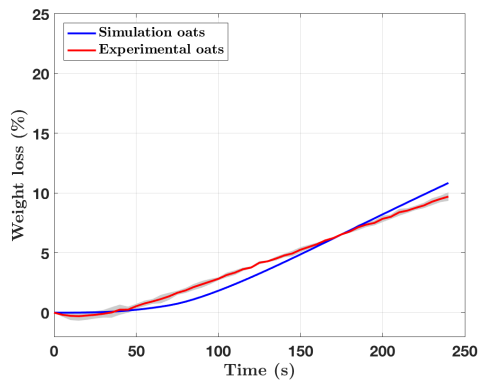

(d) $\mathrm{RMSE}=0.63 \%$

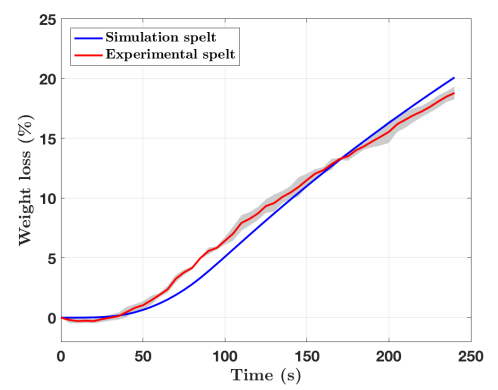

(b) $\mathrm{RMSE}=0.88 \%$

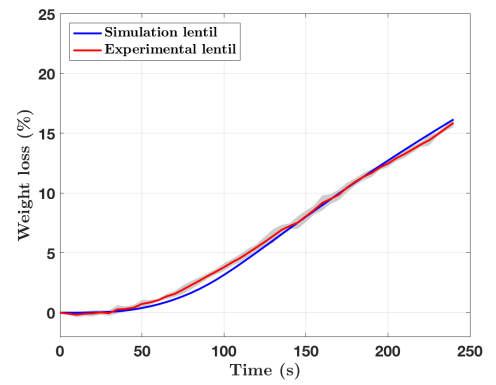

(e) $\mathrm{RMSE}=0.35 \%$

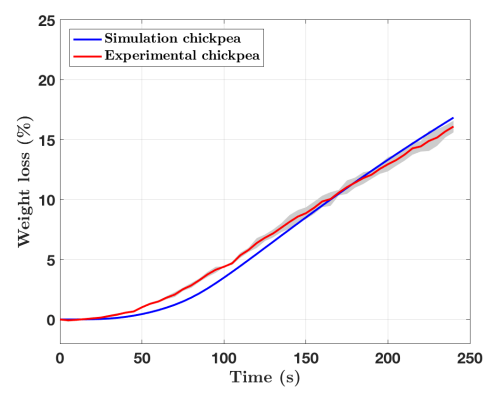

(g) $\mathrm{RMSE}=0.62 \%$

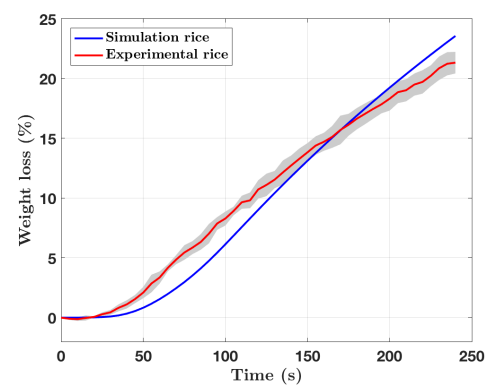

(c) $\mathrm{RMSE}=1.41 \%$

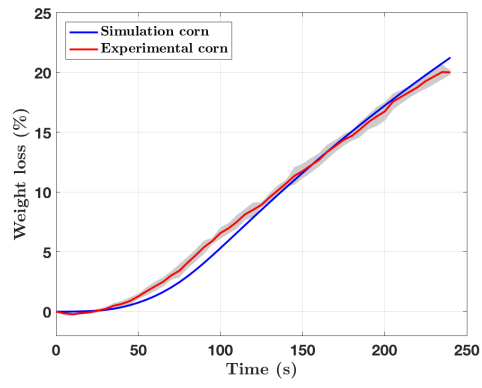

(f) $\mathrm{RMSE}=0.63 \%$

Figure 7: Comparison between the weight loss evolution obtained with the computational simulation and the experimental results for different batter compositions. The gray area in the figures represents the experimental standard deviation. The root mean square errors (RMSE) between the mean of the experimental results and the model prediction are presented under the figures. 


\section{Conclusions}

The laboratory setup that reproduced the domestic cooking environment enabled us to acquire repeatable temperature and weight loss measurements of the contact heating baking process of pancakes made with different flours. Seven batters made with seven different flours were analyzed. The apparent viscosity of the batter reflected a significant inverse dependence with the weight loss during the pancake cooking process. Batters containing oats and legume flours lost less weight than the wheat-based batter due to their high fiber and protein content, whereas the low protein and gluten-free batters (rice and corn) experienced a greater weight loss. No significant differences among the batters were observed for the average temperature at the upper side of the pancake.

According to the model proposed, the changes that the crust formation produces in the thermal contact conductance between the pan and the batter and in the heat transfer properties involve a decrease in the heat flux and consequently a decrease in the evaporation rate of the water at the bottom of the batter. The magnitude of these modifications and the temperature at which they occur have been related to the rheological properties of the batters, which in turn depend fundamentally on whether they are gluten-free or not and on their fiber and protein content. The values of the parameters obtained by fitting the model to the experimental data help to understand the behavior of batters of different composition and why the weight loss of these batters during the cooking process has a different evolution. These results can be useful in future studies of heat and mass transfer in cereal foods containing non-wheat flour batters.

\section{Acknowledgements}

This work has been funded by the Spanish Ministry of Science, Innovation and Universities through the RETOS-COLABORATION 2017 program (project RTC-2017-5965-6, ARQUE), co-financed by the European Union with ERDF; and by BSH Home Appliances Group. The 
Department of Industry and Innovation (Government of Aragon) through the research group Grant T24-17R and T07-17R (co-financed by ERDF).

\section{References}

AACC. Methods 08-01, 30-25, 32-05, 44-15a,46-10. AACC International. Approved Methods of Analysis 10th Ed., 2000.

A. Ahmad, F. M. Anjum, T. Zahoor, H. Nawaz, and A. Din. Physicochemical and functional properties of barley beta-glucan as affected by different extraction procedures. Int. J. Food Sci. Technol., 44(1):181-187, enero 2009.

M. D. Alvarez, B. Herranz, R. Fuentes, F. J. Cuesta, and W. Canet. Replacement of wheat flour by chickpea flour in muffin batter: Effect on rheological properties. J. Food Process Eng., 40(2), 2017.

R. Baixauli, A. Salvador, and S. M. Fiszman. Textural and colour changes during storage and sensory shelf life of muffins containing resistant starch. Eur. Food Res. Technol., 226(3): 523-530, enero 2008.

J. Cernela, B. Heyd, S. Keller, J. L. Bailleul, M. N. Maillard, C. Bonazzi, and B. Broyart. Experimental study of heat and mass transfer phenomena during the contact heating of solid food models. J. Food Eng., 146:99-106, 2015.

A. K. Datta. Status of physics-based models in the design of food products, processes, and equipment. Compr. Rev. Food Sci. Food Saf., 7(1):121-129, 2008.

E. de La Hera, B. Oliete, and M. Gomez. Batter characteristics and quality of cakes made with wheat-oats flour blends. J. Food Qual., 36(2):146-153, 2013. 
B. Decindio and S. Correra. Mathematical-modeling of leavened cereal goods. J. Food Eng., 24(3):379-403, 1995.

J. W. Donovan. A study of the baking process by differential scanning calorimetry. J. Sci. Food Agric., 28(6):571-578, Jun 1977.

A. H. Feyissa, K. V. Gernaey, S. Ashokkumar, and J. Adler-Nissen. Modelling of coupled heat and mass transfer during a contact baking process. J. Food Eng., 106(3):228-235, 2011.

S. Geisslitz, C.F.H. Longin, K.A. Scherf, and P. Koehler. Comparative study on gluten protein composition of ancient (einkorn, emmer and spelt) and modern wheat species (durum and common wheat). Foods, 8(409), 2019.

A. Y. Guadarrama-Lezama, H. Carrillo-Navas, César Pérez-Alonso, E. J. Vernon-Carter, and J. Alvarez-Ramírez. Thermal and rheological properties of sponge cake batters and texture and microstructural characteristics of sponge cake made with native corn starch in partial or total replacement of wheat flour. LWT-Food Sci. Technol., 70:46-54, 2016.

S. Guibert-Martin, V. Jury, B. Bouchet, G. Roellens, P. Lioret, and A. Le-Bail. Impact of the baking protocol on the structure of french crepes. J. Food Eng., 196:183-192, 2017.

M. A. Gularte, E. de la Hera, M. Gómez, and C. M. Rosell. Effect of different fibers on batter and gluten-free layer cake properties. LWT-Food Sci. Technol., 48(2):209 - 214, 2012.

N. Hesso, C. Loisel, S. Chevallier, A. Marti, P. Le-Bail, A. Le-Bail, and K. Seetharaman. The role of ingredients on thermal and rheological properties of cake batters and the impact on microcake texture. LWT-Food Sci. Technol., 63(2):1171-1178, octubre 2015.

M. Huang and H. Yang. Eucheuma powder as a partial flour replacement and its effect on the properties of sponge cake. LWT-Food Sci. Technol., 110:262-268, agosto 2019. 
R. Iribe-Salazar, R. Gutierrez-Dorado, E. Rios-Iribe, M. Carrazco-Escalante, Y. Vazquez-Lopez, O. Hernandez-Calderon, and J. Caro-Corrales. Modeling of effective moisture diffusivity in corn tortilla baking. J. Food Sci., 83(8):2167-2175, 2018.

M. Kaur and N. Singh. Studies on functional, thermal and pasting properties of flours from different chickpea (cicer arietinum 1.) cultivars. Food Chem., 91(3):403 - 411, 2005.

P. Kaushal, V. Kumar, and H. K. Sharma. Comparative study of physicochemical, functional, antinutritional and pasting properties of taro (colocasia esculenta), rice (oryza sativa) flour, pigeonpea (cajanus cajan) flour and their blends. LWT-Food Sci. Technol., 48(1):59-68, 2012.

U. Kokolj, L. Skerget, and J. Ravnik. A numerical model of the shortbread baking process in a forced convection oven. Appl. Therm. Eng., 111:1304-1311, 2017.

M. Lostie, R. Peczalski, J. Andrieu, and M. Laurent. Study of sponge cake batter baking process. ii. modeling and parameter estimation. J. Food Eng., 55(4):349-357, diciembre 2002 .

S. Martinez-Cervera, T. Sanz, A. Salvador, and S. M. Fiszman. Rheological, textural and sensorial properties of low-sucrose muffins reformulated with sucralose/polydextrose. LWTFood Sci. Technol., 45(2):213-220, 2012.

M. E. Matos, T. Sanz, and C. M. Rosell. Establishing the function of proteins on the rheological and quality properties of rice based gluten free muffins. Food Hydrocolloids, 35:150 - 158, 2014 .

S. Mercier, B. Marcos, C. Moresoli, M. Mondor, and S. Villeneuve. Modeling of internal moisture transport during durum wheat pasta drying. J. Food Eng., 124:19-27, marzo 2014. 
P. Nesvadba. Engineering Properties of Foods, volume 4, chapter Thermal properties of unfrozen foods. Taylor and Francis Group, 223-245, 4 edition, 2014.

M. A. Rao, S. S. H. Rizvi, and Ashim K Datta. Engineering properties of foods, volume 144 of Food science and technology. Taylor \& Francis, Boca Raton, 3rd ed. edition, 2005.

M. Sahagún, A. Bravo-Núñez, G. Báscones, and M. Gómez. Influence of protein source on the characteristics of gluten-free layer cakes. LWT, 94:50 - 56, 2018.

F. Sanz-Serrano, C. Sagues, A.H. Feyissa, J. Adler-Nissen, and S. Llorente. Modeling of pancake frying with non-uniform heating source applied to domestic cookers. J. Food Eng., 195:114$127,2017$.

S. Torquato and G. R. Stell. An equation for the latent-heat of vaporization. Ind. eng. Chem. Fundam., 21(3):202-205, 1982.

E. Turabi, G. Sumnu, and S. Sahin. Rheological properties and quality of rice cakes formulated with different gums and an emulsifier blend. Food Hydrocolloids, 22(2):305-312, marzo 2008.

L. Zhang, C. Doursat, F. M. Vanin, D. Flick, and T. Lucas. Water loss and crust formation during bread baking, part i: Interpretation aided by mathematical models with highlights on the role of local porosity. Dry. Technol., 35(12):1506-1517, 2017. 